\title{
Impact of Hydrogel on Physical Properties of Coarse-structured Horticultural Substrates
}

\author{
W.C. Fonteno' and T.E. Bilderback ${ }^{2}$ \\ Horticultural Substrates Laboratory, Department of Horticultural Science, Box 7609, North \\ Carolina State University, Raleigh, NC 27695-7609
}

Additional index words. polyacrylamide hydrogel, water relations, pore space, soil additive, amendments, available

water, unavailable water

\begin{abstract}
Addition of a polyacrylamide hydrogel to pine bark and pine bark + sand substrates had no effect on total porosity, regardless of incorporation rate. Container capacity was increased with increasing rate of hydrogel in both substrates. Air space in pine bark was slightly increased at the lowest rate but was reduced with higher incorporation rates. Air space in pine bark + sand was reduced with all hydrogel additions. The dry weigh', of hydrogel cubes recovered from both substrates was similar to amounts predicted. This result indicates that blending hydrogel granules into the substrates was uniform and did not contribute to variability in hydrogel studies. After allowing dry hydrogel granules to expand freely in distilled water for 24 hours, hydrogel granules expanded 317 and 372 times their dry weights at the lowest and highest rates, respectively. Reduction of expansion (in water) at higher rates may have been due to physical restriction of expansion. Conversely, recovered hydrogel cubes from substrates watered to drainage (-10\% excess) for 6 weeks absorbed 25 to 55 times their dry weight while in the container. Subsequent rehydration of extracted gels in distilled water was greater for hydrogel cubes from the pine bark + sand medium (104 to 130) than in pine bark alone (51 to 88). Because of anomalies in hydraulic conductivity and pressure plate contact, three techniques were used to study unavailable water content in gels expanded in distilled water. Hydrogel cubes placed in direct contact with the pressure plate released $\approx 95 \%$ of their water at pressures $\leq 1.5 \mathrm{MPa}$. Effectiveness of ployacrylamide gels in coarse-structured substrates is influenced by physical restrictions to expansion in the substrate and hydraulic conductivity between the hydrogel cubes and the surrounding substrate.
\end{abstract}

Hydrophilic polymers have been added to horticultural substrates to increase water-holding capacity and aeration and to reduce watering frequency. These polymers have been separated into three chemical types: starch-based, polyacrylamide, and propenoate-propenamide copolymers. Hydrogels absorb many times their weight in deinoized/distilled water. Incorporated in horticultural substrates, these gels have produced variable results in water-holding characteristics, reducing crop irrigation requirements and plant response (Bowman et al., 1990; Ingram and Yeager, 1987; Keever et al., 1989; Wang and Gregg, 1990).

All three types of hydrogels used in container substrates are affected to varying degrees by amendments normally incorporated in greenhouse and nursey production. Reports have attributed this variability to the effect of salts in container substrate solution. Foster and Keever (1990) reported high concentrations of free ions or divalent cations in solution greatly reduced absorbency of starch- based and synthetic gels. Divalent cations of $\mathrm{Ca}^{2}+$ and $\mathrm{Mg}^{2}+$ and monovalent cations of $\mathrm{K}^{+}$and $\mathrm{NH}_{4}^{+}$ were shown to reduce hydrogel hydration in solution to $\approx 10 \%$ and $20 \%$ of maximum, respectively (Bowman et al., 1990). Anions had little effect on absorption (Bowman et al., 1990; Wang and Gregg, 1990).

When incorporated into horticultural substrates, the effects of hydrogels on physical properties have also been variable. In-

\footnotetext{
Received for publication 3 Sept. 1991. Accepted for publication 30 June 1992. The use of trade names in this publication does not imply endorsement by the North Carolina Agricultural Research Service of the products named, nor criticism of similar ones not mentioned. This research was supported, in part, by erants from Industrial Services International and Aquatrols Corporation of America and the hydrogel used in this study is a commercial material distributed under the trade names "Terrasorb AG" and "SuperSorb C." respectively. Technical assistance of Beth Harden, Jerome Brewster, and Mary Lorscheider is gratefully acknowledged. The cost of publishing this paper was defrayed in part by the payment of page charges. Under postal regulations, this paper therefore must be hereby marked advertisement solely to indicate this fact.

Associate Professor.

${ }^{2}$ Professor.
}

gram and Yeager (1987) found no influence on the volume of water kept at $10 \mathrm{kPa}$. Bowman et al. (1990) showed there was no effect on physical properties even at twice the recommended rate of hydrogel addition, while Wang and Gregg (1990) reported increased water-holding capacity of $6 \%$ to $18 \%$ by volume over control substrates.

Synthetic polyacrylamides have been shown to increase substrate volume with little effect from salt amendments (Wang and Gregg, 1990). Addition of SuperSorb C (Aquatrols Corp. of America, Pennsauken, N.J.) increased weight, bulk density, and total water kept in a peatmoss : composted pine bark substrate regardless of fertilizer amendments used. Irrigation and drying cycles resulted in decreased substrate volume, water retention, and bulk density and increased noncapillary pore space. However, all values remained higher than in substrate without gel.

Results based on plant performance have also been inconclusive. Gehring and Lewis (1980) reported that marigold (Tagetes patula L.) and zinnia (Zinnia elegans Jacq.) plants grown in peat-lite substrate amended with a propenoate-propenamide copolymer hydrogel did not wilt as rapidly and had lower internal moisture tension than plants grown in unamended peat-like substrate. Wang (1989) incorporated the same type of hydrogel into peat-lite, peatmoss : bark : sand and peatmoss : bark substrates and found the hydrogel had no beneficial effect on plant growth but extended the time to wilting of Codiaeum variegatum $\mathrm{L}$. 'Norma'.

Other studies found that starch-acrylate hydrogels did not enhance growth performance of holly (Ilex $X$ 'Nellie R. Stevens' Van Lennep.) and leyland cypress (X Cupressocyparis leylandii Jacks \& Dall.) (Tomlinson and Bilderback, 1985); azalea (Rhododendron obtusum Planch. 'Hino Crimson') and boxwood (Buxus microphylla Koreana Nakai 'Wintergreen') (Keever et al., 1989); and privet (Ligustrum japonicum Thunb.) (Taylor and Halfacre, 1986). Wang and Boogher (1987) reported that chlorophytum (Chlorophytum comosum Thunb.) plants were larger 
when grown in a 1 peatmoss : 1 pine bark (v/v) substrate amended with a polyacrylamide hydrogel than in nonamended substrates. However, they found that hydrogel addition had no effect on irrigation frequency or fresh weight of Boston fern (Nephrolepis exaltata (L.) Schott. 'Rooseveltii').

Virtually all the studies reported used substrate components with high moisture-holding capacities, such as peatmoss and hardwood bark. Commercial nurseries in the eastern United States use various combinations of coarse components, such as pine bark and pine bark + sand. Pine bark substrates tend to have larger particles, more air space, and less moisture after drainage than peat- or hardwood bark-based substrates. This increased drainage is important in outdoor production to prevent overwatering during heavy precipitation but results in frequent irrigation during the growing season. Additional water-holding capacity would be desirable in these mixes if drainage characteristics were not appreciably altered. Because hydrogels hold a large quantity of water in a relatively small volume, they may have the potential to increase water-holding capacity without restricting drainage.

Synthetic hydrogels maintain structural integrity upon hydration and are less damaged by fertilizer salts than starch-based hydrogels (Wang and Gregg, 1990). A polyacrylamide gel, SuperSorb $\mathrm{C}$ was used in pine bark-containing substrates in this research. The objectives were to determine: 1) the effects of incorporation on distribution of hydrogel and resultant physical properties of amended pine bark substrates; 2) the expansion and absorption of hydrogels in water and in pine bark substrates; and 3) the available and unavailable water content of hydrogels expanded in pine bark substrates and in water alone.

\section{Materials and Methods}

A synthetic hydrogel, SuperSorb C $(99.5 \%$ copolymer acrylamide acrylate), was combined with aged pine bark $(\leq 1.3-\mathrm{cm}$ diameter) alone and 4 pine bark : 1 concrete grade $\sigma \alpha v \delta(\mathrm{v} / \mathrm{v})$. They hydrogel was incorporated into the substrates at rates of $0,0.6,1.2$, and $1.8 \mathrm{~kg} \cdot \mathrm{m}^{-3}$. The hydrogel was added as dry granules to $0.38 \mathrm{~m}^{3}$ of each substrate and mixed in a $0.76-\mathrm{m}^{3}$ capacity ribbon blender for $10 \mathrm{~min}$. Each substrate/hydrogel combination was immediately potted into 3.8-liter containers, placed in a glass greenhouse under ambient conditions, and watered daily with $\approx 10 \%$ excess for 6 weeks.

A $347-\mathrm{cm}^{3}$ sample was taken from the center of each of eight containers per treatment using an aluminum cylinder $(7.6 \times$ $7.6 \mathrm{~cm}$ diameter/height) following the procedures of Fonteno et al. (1981). Four samples were used to determine total porosity, container capacity, and air space, while the other four were examined for hydrogel incorporation, hydration, and recovery. The remaining substrate in each sampled container was used to determine water retention at $1.5 \mathrm{MPa}$, using procedures of Milks et al. (1989).

Physical properties. To determine total porosity, water-holding capacity, and air space for each substrate/application rate combination, a base plate was attached to each of the aluminum cylinders used for sampling. This aluminum base plate consisted of an inner and outer plate with eight holes in each plate. The plates were fitted together as one unit so that the holes could be aligned in the open position for drainage through the plates or rotated to a closed position to prevent any seepage of water through the plates. Each unit (cylinder with attached base plate) was placed in a Buchner funnel that had been modified to accept the unit into a fixed position where the outside plate would not move. Rubber stoppers were inserted into the bottom of the funnels to prevent drainage.

The units were rotated into the open position, and distilled water was added between the aluminum cylinder and the Buchner funnel walls to allow water to be absorbed through the base plate. Water was added slowly in a step-wise fashion as outlined in Karlovich and Fonteno (1986) to prevent air entrapment. Water level was eventually brought to the top of the substrate where it was allowed to equilibrate for an additional $15 \mathrm{~min}$ before drainage.

The base plate was then closed by carefully rotating the unit with no disturbance to the contents in the cylinder. Rubber stoppers were removed and water from around the units was allowed to drain away. A graduate cylinder was placed under each funnel, the base plate opened, and the sample allowed to drain for $60 \mathrm{~min}$.

After drainage, the units were removed from the funnels and the base plates were detached from the cylinders. Wet weights of the samples were recorded. Samples were placed in a forcedair drying oven at $110 \mathrm{C}$ for $24 \mathrm{~h}$ and dry weight recorded. Container capacity (CC) (percent volume) was defined as (wet weight - dry weight $) \div$ volume of sample. Air space (AS) was the volume of water drained from the sample $\div$ volume of sample. Total porosity (TP) was $\mathrm{CC}+\mathrm{AS}$. The effects of incorporation rate within substrate on $\mathrm{TP}, \mathrm{CC}$, and $\mathrm{AS}$ were examined using regression analysis.

An estimate of unavailable water (UW) was defined as the amount of water held at 1.5 MPa. Available water (AW) was determined for each sample as $\mathrm{CC}-\mathrm{UW}$, using pressure plate extraction and procedures of Milks et al. (1989).

Previous research describing physical property relationships has shown that TP and UW are properties of the substrate alone and are independent of container size, provided bulk densities are similar in various containers (Bilderback and Fonteno, 1987; Milks et al., 1989; Tilt et al., 1987). However, CC, AS, and AW are influenced by substrate and container size and therefore restricted to 7.6-cm-tall containers in this study.

Physical incorporation, recovery, and rehydration. Four 347$\mathrm{cm}^{3}$ samples of each treatment were examined for hydrogel content $\approx 1 \mathrm{~h}$ after the last irrigation in the greenhouse. Under $\mathrm{x} 10$ magnification, all visible hydrogel particles were recovered from each sample, cleared of substrate and debris without additional moisture, collectively weighed per sample, and placed in $\approx 200$ $\mathrm{ml}$ of distilled water for $24 \mathrm{~h}$. Excess water was removed, and hydrogels were weighed again. The rehydrated hydrogels were placed in a forced-air drying oven at $110 \mathrm{C}$ for $24 \mathrm{~h}$, and dry weight was recorded.

To compare the amounts of hydrogel expansion, three indices (water hydration, substrate hydration, and recovery) were determined. Water hydration indices were determined by hydrating five replicates of $0.21,0.41$, and $0.62 \mathrm{~g}$ of dry hydrogel granules in distilled water $(\geq 100 \mathrm{ml}$ free solution) for $24 \mathrm{~h}$. These amounts were equivalent to the amount of hydrogel predicted to be found in a $347-\mathrm{cm}^{3}$ sample of each substrate using hydrogel incorporation rates of $0.6,1.2$, and $1.8 \mathrm{~kg} \cdot \mathrm{m}^{-3}$, respectively. Substrate hydration index was calculated as: (recovered hydrogel weight - hydrogel dry weight) $\div$ hydrogel dry weight. After recovered hydrogels were allowed to hydrate in distilled water for $24 \mathrm{~h}$, a rehydration index was determined as (wet weight of rehydrated recovered hydrogel - hydrogel dry weight) $\div$ hydrogel dry weight. Mean separation with LSD was done within hydrogel rate among indices. Effect of hydrogel rate was evaluated within each index by regression analysis. 
Unavailable water in hydrogel. The amount of water held at 1.5 MPa was initially determined (technique I) using a modified procedure of Milks et al. (1989). Five replicates of $0.4 \mathrm{~g}$ of dry granules were placed into aluminum rings $(7.6 \times 2.5 \mathrm{~cm}$ diameter/height) on a $1.5-\mathrm{MPa}$ ceramic pressure plate and saturated for $24 \mathrm{~h}$. This amount of dry hydrogel granules was estimated to fill the rings without overflowing onto the plates. Because of the unexpectedly high unavailable water content obtained from the hydrogel in this experiment, additional work was necessary to explain it.

To check for full hydrogel expansion, a second experiment (technique II) was performed by first allowing dry hydrogel granules to expand freely in distilled water in a plastic tub for $24 \mathrm{~h}$. Five aluminum rings were then filled with the hydrated hydrogels and $1.5 \mathrm{MPa}$ of pressure immediately applied for 48 $\mathrm{h}$ according to normal procedures of Milks et al. (1989). The resultant dry weight of granules in the aluminum rings was $0.2 \mathrm{~g}$.

In both techniques, it was noted that many of the swollen hydrogel cubes seemed to retain their original size after pressure was applied, indicating a possible break of continuity between the hydrogel particles and the plate. Therefore, a third experiment (technique III) was performed. Hydrogel granules were allowed to hydrate freely in distilled water for $24 \mathrm{~h}$ as in technique II. Only enough hydrated hydrogel cubes were placed in each of five rings so that each cube was in contact with the pressure plate. Because the volume of the hydrogel was unknown, the water held at 1.5 MPa was expressed as percent weight rather than volume. For purposes of comparison, the data in techniques I and II were expressed in both percent volume and percent weight.

\section{Results and Discussion}

Physical properties. Incorporating sand with pine bark reduced total porosity and air space compared with pine bark alone (Table 1). Addition of hydrogel to pine bark and pine bark + sand substrates had no effect on total porosity, regardless of rate of incorporation. Container capacity increased with increasing rate of hydrogel in both substrates. Air space in pine bark was slightly increased at the lowest rate of hydrogel incorporation but was reduced with higher rates. Air space in pine bark + sand was reduced with all hydrogel rates.

Physical incorporation and recovery. Two possible physical explanations for variable results when using hydrogels in substrates are: 1) inconsistent incorporation of dry granules during blending and 2) reduced hydration of hydrogels in substrates vs. distilled water. Number, wet weight, and dry weight of hydrogel cubes recovered increased linearly with rate of incorporation in both substrates (Table 2). Subsequent rehydration of recovered hydrogel cubes followed the same trend.

The dry weight of hydrogel cubes of each hydrogel rate/substrate combination was predicted for a $347-\mathrm{cm}^{3}$ sample. Actual dry weights of hydrogel cubes recovered were very close to amounts predicted (Table 2). This result indicates that incorporation of hydrogel granules was uniform across rates and substrates.

Water hydration, substrate hydration, and expansion recovery. After allowing dry hydrogel granules to expand freely in distilled water for $24 \mathrm{~h}$, water hydration indices were determined for each hydrogel incorporation rate (Table 3). Hydrogel granules equivalent to the lowest incorporation rate expanded to 372 times their dry weight, while the higher rates resulted in lower (317) expansion indices. Reduction in expansion at the higher rates may have been influenced by small amounts of soluble
Table 1. Effects of hydrogel incorporation on total porosity, container capacity, and air space of pine bark and 4 pine bark : 1 sand $(\mathrm{v} / \mathrm{v})$ substrates. ${ }^{2}$

\begin{tabular}{|c|c|c|c|}
\hline $\begin{array}{l}\text { Substrate and } \\
\text { incorporation } \\
\text { rate }\left(\mathrm{kg} \cdot \mathrm{m}^{-3}\right)\end{array}$ & $\begin{array}{c}\text { Total porosity } \\
\text { (\% vol) }\end{array}$ & $\begin{array}{c}\text { Container capacity } \\
(\% \text { vol })\end{array}$ & $\begin{array}{c}\text { Air space } \\
(\% \text { vol }) \\
\end{array}$ \\
\hline \multicolumn{4}{|l|}{ Pine bark } \\
\hline 0 & 76.8 & 59.8 & 18.0 \\
\hline 0.6 & 76.5 & 56.1 & 20.4 \\
\hline 1.2 & 81.1 & 64.1 & 17.0 \\
\hline 1.8 & 77.7 & 63.9 & 13.9 \\
\hline $\mathrm{SE}^{\mathrm{y}}$ & 1.77 & 1.31 & 1.00 \\
\hline \multicolumn{4}{|l|}{ Significance } \\
\hline F test & NS & $* *$ & $* *$ \\
\hline L & NS & ** & -- \\
\hline Q & NS & NS & $*$ \\
\hline \multicolumn{4}{|c|}{4 pine bark : 1 sand } \\
\hline 0 & 69.0 & 58.1 & 10.9 \\
\hline 0.6 & 66.0 & 60.2 & 5.8 \\
\hline 1.2 & 69.4 & 62.3 & 7.0 \\
\hline 1.8 & 68.9 & 61.6 & 7.3 \\
\hline SE & 0.97 - & 0.60 & 0.61 \\
\hline \multicolumn{4}{|l|}{ Significance } \\
\hline $\mathrm{F}$ test & NS & $*$ & $* *$ \\
\hline $\mathbf{L}$ & NS & $* *$ & $\cdots$ \\
\hline$Q$ & NS & NS & $* *$ \\
\hline
\end{tabular}

${ }^{2}$ All analyses performed using standard aluminum soil sampling cylinders (7.6 cm i.d., $7.6 \mathrm{~cm}$ height).

yNs $* *$, Nonsignificant or linear (L) or quadratic $(\mathrm{Q})$ at $P \leq 0.01$, or $P \leq 0.05$, respectively.

ions present in the hydrogels from the manufacturing process (Bowman, 1990; Wang and Gregg, 1990) or physical restriction of the hydrogel cubes on each other or both.

Wet weight of hydrogel cubes recovered and subsequent rehydrations in distilled water (Table 2) were used to calculate substrate hydration index and recovery index for each substrate/ gel rate combination (Table 3). At container capacity in each substrate, the hydrogel cubes recovered had absorbed from 25 to 55 times their weight in water. Recovered hydrogel cubes expanded much less in the substrates than equivalent amounts did in distilled water, possibly because of: 1) lack of free water at container capacity in the substrates compared with saturation in beakers, and 2) physical resistance to expansion in the substrate.

Rehydration of recovered hydrogel cubes in distilled water resulted in increased expansion over recovered hydrogels in all treatments (as determined by LSD). Although free water was present in the rehydrated cubes, expansion was still much less than in hydrogel granules initially expanded in distilled water. Additionally, rehydration of hydrogel was greater when recovered from pine bark + sand (index 104 to 130) than from pine bark alone (index 51 to 88 ).

We thought that the reduction in water hydration index with increasing hydrogel rate was due to physical restriction alone. However, between the two substrates, more rehydration was evident in the much heavier pine bark + sand mix. Previous research has indicated that expansion of hydrogels is reduced in the presence of mono- and divalent cations found in fertilizers (Bowman et al., 1990; Foster and Keever, 1990; Wang and Gregg, 1990). Since no fertilizers were used in this study, the reduction in expansion may be due, in part, to one or more of the many leachable compounds found in pine bark (Bollen and Lu, 1970; DeVleeschauwer et al., 1982). This effect of chem- 
Table 2. Predicted and recovered amounts of hydrogel in pine bark and pine bark + sand substrates sampled from 3.8-liter containers. ${ }^{2}$

\begin{tabular}{|c|c|c|c|c|c|}
\hline $\begin{array}{c}\text { Substrate } \\
\text { and } \\
\text { incorporation } \\
\text { rate }\left(\mathrm{kg} \cdot \mathrm{m}^{-3}\right) \\
\end{array}$ & $\begin{array}{l}\text { Predicted } \\
\text { dry wt } \\
\text { gels to } \\
\text { be } \\
\text { recoveredy } \\
\text { (g) }\end{array}$ & $\begin{array}{l}\text { Dry wt } \\
\text { gel cubes } \\
\text { recovered } \\
\text { (g) }\end{array}$ & $\begin{array}{c}\text { Gel cubes } \\
\text { recovered } \\
\text { (no.) }\end{array}$ & $\begin{array}{c}\text { Wet wt } \\
\text { gel cubes } \\
\text { recovered } \\
(\mathrm{g})\end{array}$ & $\begin{array}{l}\text { Rehydration } \\
\text { wt of gel } \\
\text { cubes } \\
\text { recovered } \\
\text { (g) }\end{array}$ \\
\hline \multicolumn{6}{|l|}{ Pine bark } \\
\hline 0.6 & 0.21 & 0.22 & 30 & 5.8 & 11.8 \\
\hline 1.2 & 0.41 & 0.50 & 89 & 21.9 & 44.7 \\
\hline 1.8 & 0.62 & 0.68 & 119 & 32.9 & 57.9 \\
\hline SE & & 0.014 & 3.25 & 1.22 & 1.23 \\
\hline \multicolumn{6}{|l|}{ Significance } \\
\hline F test & & $* *$ & $* *$ & $* *$ & $* *$ \\
\hline L & & $* *$ & $* *$ & $* *$ & $* *$ \\
\hline \multicolumn{6}{|c|}{4 pine bark +1 sand } \\
\hline 0.6 & 0.21 & 0.23 & 31 & 7.6 & 23.7 \\
\hline 1.2 & 0.41 & 0.42 & 81 & 22.3 & 55.1 \\
\hline 1.8 & 0.62 & 0.67 & 110 & 33.1 & 70.6 \\
\hline & & 0.019 & 5.455 & 2.572 & 4.175 \\
\hline Significance & & & & & \\
\hline F test & & $* *$ & $* *$ & $* *$ & $* *$ \\
\hline $\mathrm{L}$ & & $* *$ & $* *$ & $* *$ & $* *$ \\
\hline
\end{tabular}

${ }^{2}$ One $347.5-\mathrm{cm}^{3}$ sample was taken from each of four containers, 6 weeks after daily irrigation. ${ }^{y}$ Amount predicted in a $347.5-\mathrm{cm}^{3}$ sample of substrate based on incorporation rate $\left(\mathrm{kg} \cdot \mathrm{m}^{-3}\right)$.

$* *$ Significant at $P \leq \mathrm{S} 0.01 . \mathrm{L}=$ linear.

Table 3. Absorption of hydrogel in distilled water, in substrates, and after extraction from substrates and rehydrated.

\begin{tabular}{|c|c|c|c|c|}
\hline $\begin{array}{l}\text { Substrate and } \\
\text { incorporation } \\
\text { rate }\left(\mathrm{kg} \cdot \mathrm{m}^{-3}\right)\end{array}$ & $\begin{array}{c}\text { Hydration } \\
\text { index }\end{array}$ & $\begin{array}{c}\text { Recovery } \\
\text { index }\end{array}$ & $\begin{array}{c}\text { Rehydration } \\
\text { index }\end{array}$ & LSD $^{w}$ \\
\hline $\begin{array}{c}\text { Pine bark } \\
0.6 \\
1.2 \\
1.8\end{array}$ & $\begin{array}{l}372 \\
317 \\
318\end{array}$ & $\begin{array}{c}\mathrm{H}_{2} \mathrm{O} / \mathrm{g} h y d r \\
25 \\
43 \\
49\end{array}$ & $\begin{array}{l}51 \\
88 \\
85\end{array}$ & $\begin{array}{r}14 \\
7 \\
9\end{array}$ \\
\hline $\begin{array}{l}\text { SE } \\
\text { Significance } \\
\text { F test } \\
\text { L }\end{array}$ & $\begin{array}{l}4.89 \\
* * \\
* *\end{array}$ & $\begin{array}{l}1.80 \\
* * \\
* *\end{array}$ & $\begin{array}{l}3.01 \\
* * \\
* *\end{array}$ & \\
\hline $\begin{array}{l}4 \text { pine bark }+ \\
0.6 \\
1.2 \\
1.8\end{array}$ & $\begin{array}{l}\text { and } \\
\qquad \begin{array}{l}372 \\
317 \\
318\end{array}\end{array}$ & $\begin{array}{l}34 \\
55 \\
50\end{array}$ & $\begin{array}{l}105 \\
130 \\
104\end{array}$ & $\begin{array}{l}33 \\
19 \\
11\end{array}$ \\
\hline $\begin{array}{l}\text { SE } \\
\text { Significance } \\
\text { F test } \\
\text { L }\end{array}$ & 4.89 & 5.38 & 10.52 & \\
\hline
\end{tabular}

${ }^{2}$ Hydration index $=$ (Wet weight of saturated gel based on incorporation rate - dry weight)/dry weight of gel.

'Recovery index $=$ (Wet weight of recovered gel - dry weight $) /$ dry weight of recovered gel.

${ }^{\mathrm{x}}$ Rehydration index $=$ Wet weight of recovered gel rehydrated in distilled water for $24 \mathrm{~h}$ - dry weight/dry weight of recovered gel.

${ }^{w}$ LSD, Mean separation of hydration index, recovery index, and rehydration index within rows at $P \leq 0.05$.

Ns,"* Nonsignificant, linear (L) at $P \leq 0.01$, respectively.

icals in pine bark may have been diluted. with the addition of sand. Also, the addition of sand to pine bark substrate may have slowed the rate of drainage and increased the time of exposure to free water, allowing greater water absorption by the hydrogel granules.
Available and unavailable water. Available and unavailable water were initially measured for all treatments using standard procedures of Milks et al. (1989). Available water content in pine bark was apparently reduced with the addition of hydrogel (Table 4). This linear reduction in available water resulted from a quadratic increase in unavailable water content with increasing

Table 4. Available and unavailable water content of pine bark and 4 pine bark : 1 sand (v/v) substrates. ${ }^{2}$

\begin{tabular}{lcc}
\hline $\begin{array}{l}\text { Substrate and } \\
\text { incorporation } \\
\text { rate }\left(\mathrm{kg} \cdot \mathrm{m}^{-3}\right)\end{array}$ & $\begin{array}{c}\text { Available water } \\
(\% \mathrm{vol})\end{array}$ & $\begin{array}{c}\text { Unavailable water } \\
(\% \text { vol })\end{array}$ \\
\hline Pine bark & & \\
0 & 23.3 & 35.2 \\
0.6 & 17.9 & 38.3 \\
1.2 & 19.8 & 44.4 \\
1.8 & 12.9 & 50.8 \\
SE & 1.18 & 0.69 \\
Significance & & $* *$ \\
F test & $* *$ & -- \\
L & $* *$ & $*$ \\
Q & NS & \\
4 pine bark : 1 sand & & 35.6 \\
0 & 22.8 & 32.4 \\
0.6 & 27.8 & 35.6 \\
1.2 & 26.9 & 44.2 \\
1.8 & 15.9 & 1.00 \\
SE & 1.01 & $* *$ \\
Significance & &.-- \\
F test & $* *$ & $* *$ \\
L &.-- & \\
Q & $* *$ & \\
\hline AII & &
\end{tabular}

${ }^{2}$ All analyses performed using standard aluminum soil sampling cylinders $(7.6 \mathrm{~cm}$ I.D., $7.6 \mathrm{~cm} \mathrm{ht})$.

'Standard error.

${ }^{\mathrm{NS}, * *, *}$ Nonsignificant, linear (L), quadratic (Q), at $P \leq 0.01$. 
rates of gel. In pine bark + sand, available water was increased at lower rates of hydrogel, then decreased with the highest rate.

This apparent increase in unavailable water content with addition of hydrogel had not been previously reported and seemed to contradict many promotional claims. Hydrogel particles have been reported to release nearly $100 \%$ of water held as soil dries (Aquatrols, 1991). To investigate this disparity, water content at $1.5 \mathrm{MPa}$ was determined for hydrogel alone.

Dry hydrogel granules were placed into aluminum rings and saturated for $24 \mathrm{~h}$, and pressure was applied (Table 5, technique I). The resulting unavailable water content was $13.8 \%$ by volume. Previous research (Klute, 1986) indicated water content values at $1.5 \mathrm{MPa}$, for a mixture of components will generally be an average of the values for the components alone. Pine bark and pine bark + sand substrates had higher unavailable water contents than the hydrogels alone (Table 4). However, unavailable water content was not intermediate when hydrogels were incorporated into the substrates, but was higher than in either of the substrates alone. To investigate this discrepancy, a second experiment was conducted.

Gel cubes were observed to continually change volume with water content. This change in volume may also influence a change in water conductivity among hydrogel particles. Dry hydrogel granules were allowed to hydrate freely in distilled water for $48 \mathrm{~h}$, then placed into the aluminum rings and pressure (1.5 MPa) was applied (technique II). The resulting dry weight of hydrogel granules in technique II was $0.2 \mathrm{~g} / \mathrm{sample}$ compared with $0.4 \mathrm{~g}$ in technique I. Because the sample rings for the 1.5 $\mathrm{MPa}$ measurements were filled to equal volumes in both experiments, full expansion of hydrogel granules was not realized in technique I. This restriction may be a demonstration of what occurred with these hydrogel granules in the substrate.

The unavailable water content in technique II was about half the volume in technique I. Visual observation of the samples after pressure was removed, but before samples were ovendried, showed that the hydrogel cubes in contact with the pressure plate were collapsed (and presumed dehydrated), while the cubes in the top portion of the aluminum rings seemed fully hydrated. When hydrogel granules in the lower portion of the sample rings were dehydrated, contact among the hydrogel

Table 5. Unavailable water of a polyacrylamide hydrogel as affected by measurement technique.

\begin{tabular}{lcccc}
\hline \hline & $\begin{array}{c}\text { Unavailable } \\
\text { water } \\
(\% \text { vol })^{y}\end{array}$ & $\begin{array}{c}\text { Wt at } \\
\text { saturation } \\
(\mathrm{g})\end{array}$ & $\begin{array}{c}\text { Wt at } \\
1.5 \mathrm{MPa} \\
(\mathrm{g})\end{array}$ & $\begin{array}{c}\text { Unavailable } \\
\text { water } \\
(\% \mathrm{wt})^{\mathrm{x}}\end{array}$ \\
\hline I & 13.8 & 94.4 & 16.23 & 17.2 \\
II & 6.6 & 91.7 & 7.87 & 8.6 \\
III & --- & 35.1 & 1.50 & 4.3 \\
SE & 1.08 & 0.20 & 0.40 & 0.4 \\
Significance & $*$ & $*$ & $*$ & $*$
\end{tabular}

'Technique: $\mathrm{I}=\mathrm{Gel}$ granules $(0.4 \mathrm{~g})$ placed into aluminum rings $(7.6$ $\mathrm{cm}$ i.d., $2.5 \mathrm{~cm}$ height), then saturated for $24 \mathrm{~h}$ before pressure applied. II = Gel granules were allowed to freely hydrate for $48 \mathrm{~h}$, aluminum rings filled with hydrated gels (recovered gel dry weight $=0.2 \mathrm{~g}$ ). III = Gel granules were allowed to freely hydrate for $48 \mathrm{~h}$; a single layer of saturated gel cubes placed into rings so all cubes were in contact with pressure plate; then pressure applied (recovered gel dry weight $=0.064 \mathrm{~g})$.

${ }^{y}$ Unavailable water (percent volume) $=[$ (weight at $1.5 \mathrm{MPa}$ - dry weight)/ring volume] * 100 .

${ }^{x}$ Unavailable water $($ percent weight $)=($ weight at $1.5 \mathrm{MPa} /$ weight at saturation) $* 100$

* Separation by ANOVA, $P \leq 0.05$. granules in the upper portion of the sample rings was broken with the pressure plate, resulting in no water movement from the remaining water-containing granules. From this experiment, it seemed that conductivity among hydrogel particles could be easily broken and could influence the movement of water from the hydrated cubes to the surrounding materials.

To test the potential of hydrated granules to release water, a third analysis was done using fully hydrated hydrogel cubes (like technique II), but using only a single layer of hydrogel cubes in each aluminum ring so all cubes were in contact with the cereamic pressure plate (technique III).

Since bulk volume of hydrogel cubes in technique III was unknown, unavailable water content was expressed on a percent weight basis and compared with results in techniques I and II. Unavailable water content in technique III was $4.3 \%$ by weight, about one-fourth that for technique I and half that for technique II. The unavailable water value in technique III supports manufacturers claims that $\approx 95 \%$ of the water contained in the hydrogel cubes would be held under tensions that could be overcome by plant roots. However, the question of "availability" seems more complex.

An examination of these procedures may provide some insight into the physical mechanism involved in the absorption, release, and movement of water in hydrogel-containing substrates. One of the main precautions in extracting water at 1.5 $\mathrm{MPa}$ is to assure intimate contact between the substrate and the plate (Klute, 1986). Additionally, we recommend that the height of substrate sample by $\leq 2.5 \mathrm{~cm}$ to assure conductivity from the plate to the top of the sample. The cylinder dimensions used in all three techniques $(7.6 \mathrm{~m} \times 2.5 \mathrm{~cm}$ diameter/height $)$ provided a volume $(115 \mathrm{ml})$ one-third of the sample volume used for the hydrogel extraction experiments $(7.6 \times 7.6 \mathrm{~cm}$ diameter/height $)$. The amount of hydrogel used in technique I $(0.4 \mathrm{~g})$ was determined as the equivalent amount of hydrogel predicted to be recovered from substrate samples with the middle rate of hydrogel addition $\left(1.2 \mathrm{~kg} \bullet \mathrm{m}^{-3}\right.$, Table 2$)$. Using the data from the pine bark substrate in Table 2 , the mean hydroge 3 granule weight was $0.005 \mathrm{~g}$ ( $1.25 \mathrm{~g}$ dry weight gels recovered $\div 238$ granules).

The difference in unavailable water content among the three techniques seems to be a function of physical contact among the hydrogel particles and the pressure plate. This inequality resulted in varying degrees of conductivity, which was a function of the number of granules in each sample, The more granules present, the more particle contacts and the more opportunity to break conductivity. The hydrated hydrogel particles in all samples contained water that could be considered $95 \%$ "available." However, the degree of "availability" was greatly influenced by conductivity from particle to particle. Therefore, the differences in unavailable water content in techniques I, II, and III can be attributed to a lack of unsaturated hydraulic conductivity between the hydrogel cubes, a loss of contact between the cubes and the pressure plate, or both.

The distance from which a root can extract moisture from a substrate depends on the moisture content and the unsaturated hydraulic conductivity of the substrate (Kramer, 1983). Although almost all the water inside the swollen hydrogel cubes can be extracted, contact with the source of tension must be maintained, as evidenced by the results in Table 5. When. this contact is broken, removal of water ceases, as indicated by visual observations of samples in technique II.

Coarse-structured substrates, such as pine bark and pine bark + sand, were designed to drain rapidly to compensate for the relatively shallow containers in which they are used (Spomer, 
1975). Unsaturated hydraulic conductivity decreases with increased drainage characteristics and is presumed to be very low in these two substrates. The degree to which water in hydrogel cubes is "available" to plants would be influenced by root contact with or proximity to hydrogel cubes.

Water passing from a swollen hydrogel cube to surrounding substrate is not a function of the moisture gradient between the cube and substrate, but rather a function of tension exerted on the hydrated cube. This tension is influenced by the matrix potential of the substrate and conductivity between the hydrogel cube and the substrate. If conductivity between the cube and substrate is broken, water movement would cease. This interruption would mean that water extracted by roots from the surrounding substrate would not necessarily be replaced by water from the hydrogel cubes. Indeed, the loss of moisture in the substrate surrounding the hydrogel cube could decrease the unsaturated hydraulic conductivity or break contact completely. This event could result in an oasis effect, whereby the root could suffer from lack of water even though water was close by. The effects of this condition would be more pronounced in newly planted containers with smaller root systems. Conversely, wellestablished root systems have been observed with roots growing into and through hydrated hydrogel cubes (personal observations). In coarse-structured mixes, there is no conclusive evidence that roots grow better surrounding hydrogel cubes than in other parts of the substrate.

Because the calculation of available water content involves the 1.5-MPa measurement, values for AW for gel-containing coarse substrates (such as in Table 4) may be erroneous by underestimating water actually available to the root system. However, total porosity, container capacity, and air space measurements are not affected,

Overall mechanism. In this study, hydrogel expanded much less in the substrates than in distilled water. This lack of expansion may have been due to both physical and chemical influences from the substrates. Almost all the water absorbed by the hydrogel cubes alone could be extracted at tensions $\leq 1.5$ $\mathrm{MPa}$. However, in the substrates, contact between hydrogel cubes and surrounding material was not always evidenced, and a considerable portion of the hydrogel's water content may not have been extracted at $1.5 \mathrm{MPa}$.

From previous research and that presented here, the overall effectiveness of hydrogels in horticultural substrates may be influenced by: 1) incorporation rate, 2) physical restrictions to expansion by the substrate, 3 ) chemicals present in the substrate (in addition to fertilizer effects), 4) unsaturated hydraulic conductivity between the substrate and hydrogel cubes, 5) physical proximity of roots to hydrogel cubes, and 6) hydrophilic nature of the hydrogel cubes over surrounding substrate.

\section{Literature Cited}

Aquatrols. 1991. Water management products user's guide. Aquatrols Corp., Pennsauken, N.J.

Bilderback,. T.E. and W.C. Fonteno. 1987. Effects of container ge- ometry and media physical properties on air and water volumes in containers. J. Environ. Hort. 5(4):180-182.

Bollen, W.B. and K.C. Lu. 1970. Sour sawdust and bark- Its origin, properties and effects on plants. U.S. Dept. Agr. For. Serv. Res. Paper PNW-108, Washington, D.C.

Bowman, D.C., R.Y. Evans, and J.L. Paul. 1990. Fertilizer salts reduce hydration of polyacrylamide hydrogels and affect physical properteis of gel-amended container media. J. Amer. Soc. Hort. Sci. 115:382-386.

DeVleeschauwer, D., O. Verdonck, and P. Van Assche. 1982. Phytotoxicity of refuse compost. Staff, compost science/ land utilization. Composting-theory and practice for city, industry and farm. JG Press, Emmaus, Pa. p. 54-60.

Fonteno, W.C., D.K. Cassel, and R.A. Larson. 1981. Physical properties of three container media and their effect on poinsettia growth. J. Amer. Soc. Hort. Sci. 106:736-741.

Foster, W.J and G.J. Keever. 1990. Water absorption of hydrophilic polymers (hydrogels) reduced by media amendments. J. Environ. Hort. 8:113-114.

Gehring, J.M. and A.J. Lewis, III. 1980. Effect of hydrogel on wilting and moisture stress of bedding plants. J. Amer. Soc. Hort. Sci. 105:511-513.

Ingram, D.L. and T.H. Yeager. 1987. Effects of irrigation frequency and a water-absorbing polymer amendment of ligustrum growth and moisture retention by a container medium. J. Environ. Hort. 5:1921.

Karlovich, P.T. and W.C. Fonteno. 1986. Effect of soil moisture tension on the growth of chrysanthemum in 3 container media. J. Amer. Soc. Hort. Sci. 111:191-195.

Keever, G.J., G.S. Cobb, J.C. Stephenson, and W.J. Foster. 1989. Effect of hydrophilic polymer amendment on growth of container grown landscape plants. J. Environ. Hort. 7:52-56.

Klute, A. 1986. Water retention: Laboratory methods, p. 635-662. In: A. KIute (ed.). Methods of soil analysis, Part 1. Physical and mineralogical methods. Monogr. 9, Amer. Soc. Agron, Madison, Wis.

Kramer, P.J. 1983. Water relations of plants. Academic, New York. $489 \mathrm{pp}$.

Milks, R.R., W.C. Fonteno, and R.A. Larson. 1989. Hydrology of horticultural substrates: II. Predicting physical properties of media in containers. J. Amer. Soc. Hort. Sci. 114:53-56.

Spomer, L.A. 1975. Small soil containers as experimental tool: Soil water relations. Commun. Soil Sci. Plant Anal. 6:21-26.

Taylor, K.C. and R.G. Halfacre. 1986. The effect of hydrophilic polymer on media water retention and nutrient availability to Ligustrum lucidium. HortScience 21:1159-1161.

Tilt, K.M., T.E. Bilderback, and W.C. Fonteno. 1989. Particle size and container size effects on growth of three ornamental species. J. Amer. Soc. Hort. Sci. 112(6):981-984.

Tomlinson, J.D. and T.E. Bilderback. 1985. The effects of moisture extenders, bentonite and irrigation on a pine bark medium and growth of 'Nellie R. Stevens' holly and leyland cypress. Proc. Southern Nurserymens' Assn. Res. Conf. 29:92-96.

Wang, Y.T. 1989. Medium and hydrogel affect production and wilting of tropical ornamental plants. HortScience 24:941-944.

Wang, Y.T. and C.A. Boogher. 1987. Effect of a medium-incorporated hydrogel on plant growth and water use of two foliage species. J. Environ. Hort. 5:125-127.

Wang, Y.T. and L.L. Gregg. 1990. Hydrophilic polymers-their response to amendments and effect on properties of a soilless potting mix. J. Amer. Soc. Hort. Sci. 115:943-948. 